\title{
CARACTERÍSTICAS SEMINAIS DE OVINOS (Ovis aries) SUBMETIDOS A TRATAMENTOS COM DIMETIL SULFÓXIDO (DMSO) \\ M.V. FERRARI ${ }^{1}$; R.R. WEISS ${ }^{1}$; A. FOLADOR ${ }^{2}$; F.L. RIBEIRO ${ }^{3}$; S.T.S. COLLODEL ${ }^{3}$ \\ ${ }^{1}$ Departamento de Medicina Veterinária. ${ }^{2}$ Curso de Pós-Graduação em Ciências Veterinárias. ${ }^{3}$ Curso de Medicina Veterinária, Setor de Ciências Agrárias, Universidade Federal do Paraná
}

Com o objetivo de observar os efeitos da aplicação tópica de Dimetil Sulfóxido (DMSO - Dimeson Gel), na dosagem de 1g/Kg de peso vivo, sobre as características seminais de ovinos, foram utilizados 9 reprodutores Hamshire Down de 16 meses de idade e peso vivo médio de $50 \mathrm{Kg}$, divididos em 3 grupos de 3 animais cada, conforme local de aplicação do produto, sendo um grupo controle (GI), um grupo que recebeu aplicação do DMSO na bolsa escrotal (GII) e um grupo que recebeu aplicação do produto no jarrete (GIII). As amostras seminais foram colhidas com vagina artificial e avaliadas semanalmente, seguindo-se as normas e procedimentos do Colégio Brasileiro de Reprodução Animal (CBRA), durante 18 semanas consecutivas, abrangendo 2 gametogêneses completas, uma anterior (período preliminar - PP) e outra logo após o início dos tratamentos (período experimental - PE). As características seminais estudadas foram volume do ejaculado $(\mathrm{ml})$, turbilhonamento (0-5),motilidade espermática individual (\%), concentração espermática $\left(\operatorname{sptz} \times \mathbf{1 0}^{3} \mathrm{~mm}^{3}\right), \mathrm{n}^{0}$ total de espermatozóides no ejaculado (milhões de espermatozóides) e defeitos espermáticos totais (\%). No PP os resultados médios encontrados foram 1,06 $( \pm 0,28), 1,14$ $( \pm 0,09), 1,15( \pm 0,15)$ e $1,10( \pm 0,06) \mathrm{ml} ; 4,73( \pm 0,25), 5,0( \pm 0,0), 4,89( \pm 0,19)$ e $4,93( \pm 0,05) ; 76,48( \pm 4,72), 80,18( \pm 0,32), 76,48$ $( \pm 4,72)$ e $77,71( \pm 2,14) \% ; 2308,63( \pm 189,99), 2420,36( \pm 6,81), 2371,11( \pm 93,18)$ e $2366,70( \pm 55,99) ; 2427,50( \pm 575,97), 2781,93$ $( \pm 227,14), 2740,70( \pm 314,13)$ e $2650,04( \pm 193,83) ; 2,40( \pm 0,48), 2,16( \pm 0,31), 3,09( \pm 1,43)$ e $2,55( \pm 0,48) \%$, para os grupos GI, GII, GIII e total, respectivamente, não havendo diferenças estatísticas significativas entre os grupos. No PE os resultados médios encontrados foram $1,06( \pm 0,21), 1,06( \pm 0,21), 1,17( \pm 0,22)$ e $1,10( \pm 0,06) \mathrm{ml} ; 4,88( \pm 0,12), 4,96( \pm 0,07), 4,96( \pm 0,07)$ e $4,93( \pm 0,05) ; 77,22( \pm 3,38), 80,36( \pm 0,32), 79,07( \pm 0,32)$ e 78,88 $( \pm 1,61) \% ; 2303,33( \pm 197,01), 2441,85( \pm 32,51), 2387,77$ $( \pm 103,88)$ e $2377,65( \pm 69,81) ; 2417,82( \pm 393,57), 2582,74( \pm 289,71), 2786,74( \pm 457,46)$ e $2595,77( \pm 184,81) ; 2,83( \pm 0,93), 1,85$ $( \pm 0,28), 2,85( \pm 0,37)$ e $2,51(0,57) \%$, para os grupos GI, GII, GIII e total, respectivamente, não havendo diferenças estatísticas significativas entre os grupos e entre os períodos. Concluiu-se que, para as caraterísticas avaliadas, o uso de DMSO, no protocolo utilizado, não causou quaisquer alterações seminais. 